\title{
Results of Basic Learning Pattern's Learned by Memorization Learning Model
}

\author{
Dina Ampera $^{1 *}$ Nurhayati $^{1}$, Farihah $^{1}$, Rosnelli $^{1}$ \\ \{*dinaampera@unimed.ac.id \} \\ Universitas Negeri Medan, Medan, Indonesia ${ }^{1}$
}

\begin{abstract}
This study aims to find out the basic learning outcomes of the pattern learned by memorization learning model for students in Vocational High School 3 Pematangsiantar as a population, with the instrument using the learning outcomes test, then analyzed by $t$ test. The results of the analysis showed that the learning outcomes learned by conventional learning showed the average results of (57.03), and the learning outcomes learned using the memorization learning model (72.03). Data distribution of learning outcomes with conventional learning is normally distributed where $0.151<0.157$ and student learning outcomes data with learning memorization learning models are normally distributed where $0.079<0.151$ and homogeneous variance data for $\mathrm{f}$ count $1.71<\mathrm{f}$ table 1.82 . It was concluded that learning outcomes with memorization learning models were better than conventional learning where the test results showed $t-4.761<\mathrm{t}$ table 1.67. So it proved that there was no effect of student learning outcomes that were learned using memorization learning models with students who were taught using conventional learning. This means that the use of learning memorization learning models can be used as alternative learning in schools.
\end{abstract}

Keywords: Learning, outcomes, pattern, memorization, learning model.

\section{Introduction}

Education that is able to support development in the future is education that is able to develop the potential of students, so that those concerned are able to face and solve the problems of life they face. Education is also one of the most important human needs in living his life, without human education it will be difficult to develop and become backward, absolute education must be continuously carried out continuously because education does not know time and is a process that continues throughout human life, both through formal and independent channels. The learning process is an educational process in which students develop knowledge, thinking skills and psychomotor skills through interaction with learning resources designed in the syllabus and learning design in the form of learning activities. Students do learning activities by observing, asking questions, gathering information, associating or analyzing, and communicating what has been found in the analysis activity. The direct learning process produces knowledge and skills or what is called the instructional effect.

Vocational High School students, are potential human resources who have the ability to live independently with the skills and mastery of knowledge from the programs chosen and owned to be able to directly apply the skills in available jobs. Vocational High Schools as part of secondary education have the following objectives: 1) Preparing students to enter the workforce and develop professional attitudes; 2) Preparing students to be able to choose a 
career, be able to be competent and develop themselves; 3) Prepare a professional workforce in the future, 4) Preparing graduates to become productive, adaptive and creative citizens.

Currently the world of education is faced with a difficult situation where graduates are not ready to use as expressed, that the closer to the world of globalization, especially information technology, the more it is deemed necessary to comprehensively improve education. The weakness of the resources of Vocational High School graduates is largely due to the lack of mastery of competencies and sub-competencies given in Vocational High Schools. The achievement of educational goals and basic competency patterns focuses on students' knowledge in understanding the basic pattern of fashion clothing including body patterns, skirt patterns and arm patterns, construction patterns, finished patterns, changing patterns according to design. The low learning outcomes occur because learning tends to be conventional, namely the teacher-oriented learning approach, so that during the learning process the students are less active, the teacher still draws a pattern on the blackboard, while the students take the drawing pattern, by paying attention to the teacher.

The teacher's role in class management is especially important in creating an attractive learning atmosphere, because in principle, the teacher holds two tasks as well as the main problem, namely teaching and classroom management. Conversely, management problems are related to efforts to create and maintain learning conditions so that the learning process can take place effectively and efficiently in order to achieve learning goals [1]. The ability of students to ask and express ideas is very low, so the teacher asks students to ask questions that are not yet understood. Joyce \& Weil write a learning model is a plan or pattern that is used as a guide in planning learning or tutorial learning and to determine learning tools and direct in designing learning to help students achieve learning outcomes [2].

Memorizing is an active effort to enter information into the brain. Lorayne (2008) said that there are people who can remember information quickly, but cannot maintain it for a long time. This is due to the lack of empowering memory capabilities. Furthermore, Joyce \& Weil (2009) suggested that the learning model has elements: 1) Syntagmatic; 2) Social System; 3) Reaction Principle; 4) Support System; 5) Instructional Impact and Companion Impact. The learning model of memorization is believed to be able to improve the results of basic learning patterns because it is supported by several support systems in the form of pictures, concrete assistance, films and other audiovisual material useful especially to increase sensory wealth in the associations created which can facilitate students' learning.

Basically conventional learning that is known to often use the lecture method, tends to be oriented towards the material listed in the curriculum and textbooks, and rarely relate the material discussed with the real problems that exist in everyday life. Syahrul (2013) explained that conventional learning is characterized by the teacher teaching more about concepts not competency, the goal is that students know something not able to do something and when the learning process students listen more [3]. When the teacher explains the material, students tend to be quiet and listen to what is explained by the teacher, students do not argue if there are things that want to be asked related to the material in the book. However, it is not enough to provide variation in teaching and learning activities in the classroom. Because there are still a number of teaching skills that can be applied by teachers in learning and are the basis of the skills or knowledge for teachers in teaching that must be possessed in addition to knowledge of methods, strategies, and other learning models. According to Kholik (2011) the advantages of conventional learning are: a) various information that is not easily found elsewhere, b) convey information quickly, c) generate interest in information, d) teach students the best way to learn by listening, e) Easy used in the teaching and learning process, while his friendship is: a) not all students have a way to learn by listening, b) often there is difficulty in keeping 
students interested in what is learned, c) students do not know what their goals are learning on that day , d) emphasis is often only on the completion of tasks, e) its absorption is low and quickly lost due to memorization [4]. In connection with this matter Ampera (2017), writes that utilizing learning models that are in accordance with the material can improve learning outcomes, and Ampera [5] exposure also explains that a teacher should be able to utilize learning strategies that are appropriate to the needs of the student's skills. Conventional learning is still carried out on the assumption that a knowledge can be transferred completely from the teacher's mind to the student. Conventional teaching methods have so far emphasized the task of the teacher to give instructions or lectures during the learning process, while students only receive passive learning.

The Memorize Learning model (information processing) has advantages and effectiveness to be used in learning, because the information processing model emphasizes how one thinks to be able to understand the concept of facts and can apply the concept to produce simple technological work related to human needs. The most important factor that influences learning is what students have known, so that the concepts that exist in the cognitive structure of students are very important in their existence so that students can learn correctly. To implement this model is to know how the brain works. By learning and knowing the work of the brain, we understand how to memorize according to the way the brain works, so memorizing becomes very easy, the spirit of memorization also increases. Whatever material form is memorized with old memories is not a momentary memory. The most effective form of personal strength actually comes from competencies based on knowledge; it is important to shape feelings that are getting better and lead us to success.

Erwin (2012) mentions there are three basic things that become the pillars of memorizing magic memory, namely: 1) Imagination is the ability to imagine something in the mind, its form in the form of visual images of the brain, 2) Association is the ability to connect something with others in mind, and color will become one of the reinforcing factors of the association, 3) Location is the ability of the brain to remember an object that has an image and association, and its condition is in a special location so it is easy to be recalled when needed. Memory for learning and daily life is supported by two basic activities, namely memorizing and recalling activities. Memorization is an active effort to enter information into the brain, whereas remembering is an active effort to release information from the brain. Meanwhile, the learning model includes four stages: clarifying dimensions, developing relationships, enhancing sensory images, and making repetitions. These stages are based on the principle of attention and techniques to improve memory (the techniques for enhancing recall). A memorization model specifically designed to increase the capacity of students to store and obtain information.

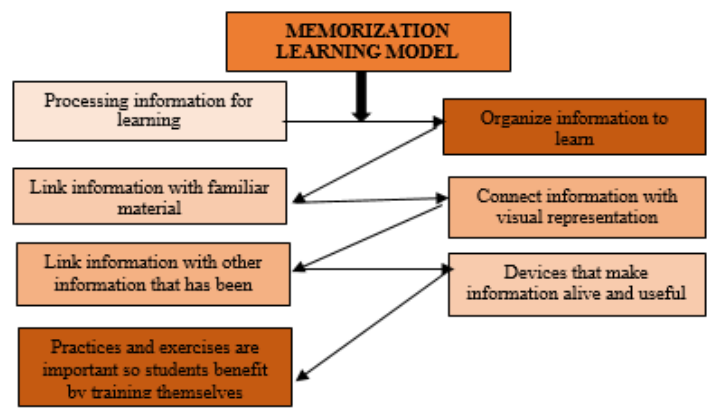

Fig. 1. Cycle of the Memorization Learning Model 
This model educates the sensibility of intellectual power, increases awareness of the ability to master unknown material, as well as thinking skills and attention to the environment. The second result is an increase in the capacity of depicting and realizing creative forms of thinking that are part of more convergent and information-oriented learning..

\section{Methodology}

This research is a quasi-experimental study with a population of 96 students, with the provision of sampling using simple random sampling technique. This study involved 2 classes that were given different treatments, namely before the treatment, the sample of this study was grouped into 2 groups, namely the memorization learning model class and the control class taught with conventional learning. Before the treatment the students were given the same material in the time of delivery and the same teacher before the treatment, and after the treatment, the post test was given to determine the development of students' knowledge after the treatment. As for the steps of research memorization learning as shown in Figure 2 below.

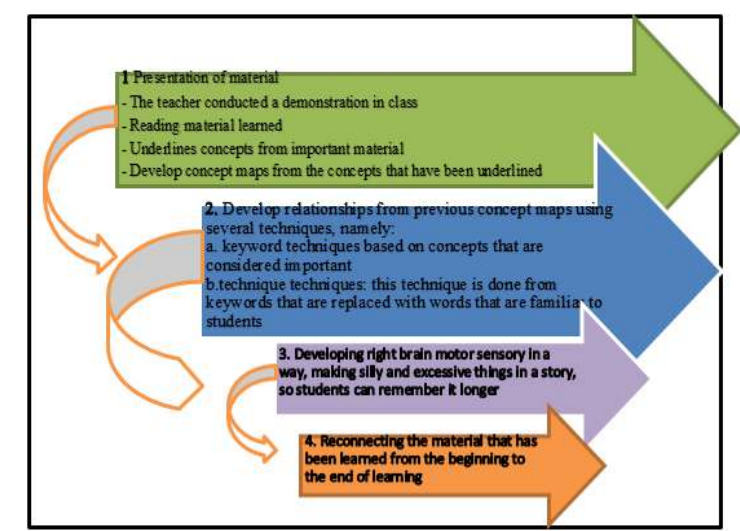

Fig.2. Research design of Memorization Learning Model

The research data is in the form of learning outcomes after learning treatment. Instrument testing was conducted to obtain tools in collecting valid and reliable data, then the valid instruments and the reliable were used to capture changes from students. To find out the validity of the learning outcomes test, the bicerial point correlation formula is used. Furthermore, the $\mathrm{r}$ count price is consulted with the $\mathrm{r}$ count price at a significant level of $5 \%$. If $\mathrm{r}^{\text {count }}>\mathrm{r}$ table, the test item is valid. The testing criteria are: accept Ho if $t<t 1-\alpha$ and $\mathrm{Ho}$ are rejected if $t$ has other prices. If $r{ }^{\text {count }}>r$ table, the test item is valid. The testing criteria are: accept Ho if $t<t 1-\alpha$ and $H o$ are rejected if $t$ has other prices. If the data analysis shows that $t \geq t 1-\alpha$ then the Ha hypothesis is accepted that there is the influence of memorization learning model on learning outcomes. 


\section{Result and Discussion}

The study was conducted at the Vocational High School by using the quasi-expansive method, in the experiment class using memorization learning models, while in the control class with conventional learning. Based on learning outcomes data using conventional learning, the average values (57.03) and standard deviations (14.16) were obtained with the highest score 85 and the lowest value 35 . Frequency distribution of learning outcomes using conventional learning is seen in Table 1 below this.

Table 1. Data Distribution of Learning Outcomes on a Basic Pattern with conventional learning.

\begin{tabular}{cccc}
\hline Class & Interval & Frequency & Percentage \\
\hline 1 & $35-43$ & 5 & 15,6 \\
2 & $44-52$ & 8 & 25,0 \\
3 & $53-61$ & 9 & 28,1 \\
4 & $62-70$ & 5 & 15,6 \\
5 & $71-79$ & 2 & 6,3 \\
6 & $80-88$ & 3 & 9,4 \\
\hline & Amount & 32 & 100 \\
\hline
\end{tabular}

Data on the basic learning outcomes of the pattern were given memorization learning model, obtained on average (72.03) and standard deviation (10.82) with the highest score (90) and the lowest value (50). This memorization learning model can guide students to be actively involved in the learning process by discussing it. Students' direct involvement in the learning process makes the learning process that is passed can be more meaningful, because it is not only focused on listening to the teacher's explanation.

This memorization learning model is able to guide students to be actively involved in the learning process. The memorization learning model can direct students to be actively involved in the basic learning process patterns can discuss, and involve students directly in learning activities so that learning becomes more meaningful, because it is not only focused on listening to the teacher's explanation. Learning also makes students better show interaction between friends, because based on the observations of researchers during the learning process, the existence of this discussion process makes two-way communication happen.

In addition to good interaction, learning is also more fun because in phase 3 , it is to improve students' ability to work in groups, discuss and do assignments, besides that students eagerly express their imagination in a picture of the types of fashion patterns. Although at the first meeting students were still lacking in sensory improvement, but at the second meeting, the imagination of students' images was much better and creative. This is based on interviews with 3 students after the learning process which states that with the activities carried out while doing group work in drawing the basic pattern of clothing, making students more excited because there is activity carried out. But this increase is not better than that obtained by students in the experimental class. This is because conventional learning has not been able to make students active in learning, student interest only appears when the teacher displays pictures of examples of body patterns and pattern descriptions with the help of power point media. Students listen more to the explanation of the material from the teacher, so that it is less constructive in understanding the drawing of patterns and changing the basic pattern according to the model, as a result the learning seems to be passive, because students tend to listen and record. Hearing and noting activities alone are not necessarily good for helping to 
memorize and understand, even making learning tend to be boring which eventually leads to indifference to learning.

Table 2. Distribution of Learning Outcomes Basic patterns given Model of Learning Memorization

\begin{tabular}{cccc}
\hline \multicolumn{4}{c}{ Learning } \\
\hline Class & Interval & Frequency & Percentage \\
\hline 1 & $50-56$ & 3 & 9.4 \\
2 & $57-63$ & 4 & 12.5 \\
3 & $64-70$ & 6 & 18.8 \\
4 & $71-77$ & 10 & 31.3 \\
5 & $78-84$ & 5 & 15.6 \\
6 & $85-91$ & 4 & 12.5 \\
\hline & Amount & 32 & 100 \\
\hline
\end{tabular}

Data on trend level learning outcomes Basic Patterns with conventional learning are seen in table 3 below.

Table 3. Trend Level of Basic Pattern Learning Outcomes with conventional learning

\begin{tabular}{cccc}
\hline Interval class & Frequency & Percentage & Category \\
\hline $90-100$ & 0 & 0,0 & Very \\
$80-89$ & 3 & 9,4 & Good \\
$70-79$ & 6 & 18,8 & Enood \\
$<70$ & 23 & 71,9 & Less \\
\hline Amount & 32 & $100 \%$ & \\
\hline
\end{tabular}

Based on Table 3 above, out of 32 samples there were 3 (9.4\%) getting good learning outcomes, 6 (18.8\%) had enough learning, and 23 (71.9\%) had less learning outcomes.

Table 4. Trend Level of Basic Pattern Learning Outcomes with Memorization Learning Model

\begin{tabular}{cccc}
\hline Interval class & Frequency & Percentage & Category \\
\hline $90-100$ & 3 & 9,4 & Very \\
$80-89$ & 6 & 18,8 & Good \\
$70-79$ & 13 & 40,6 & Enood \\
$<70$ & 10 & 31,3 & Less \\
\hline Amount & 32 & $100 \%$ & \\
\hline
\end{tabular}

Based on Table 4 it is explained that out of 32 samples there were $3(9.4 \%)$ obtained very good learning outcomes, 6 (18.8\%) got good learning outcomes, 13 people (40.6\%) got enough learning outcomes and $10(31.3 \%)$ learning outcomes are lacking categories. Exposure to the average treatment value in the experimental class and control class is shown in table 1 below. 
Table 5. Average Values of 1st, 2nd and 3rd Meeting Students of Experiment Class and control class

\begin{tabular}{lcc}
\hline Meeting & \multicolumn{2}{c}{ Average } \\
\cline { 2 - 3 } & Experimental class & Control class \\
\hline Learning 1 & 90.25 & 71.90 \\
Learning 2 & 91.50 & 79.00 \\
Learning 3 & 91.75 & 82.00 \\
\hline
\end{tabular}

From the learning outcomes data taught with memorization learning model is better than the learning outcomes taught with conventional learning. Therefore, it is expected that teachers need to rely on memorization learning models in Basic Pattern learning, because by using memorization learning models will train students to be more creative and faster in memorizing something related to understanding the pattern of fashion patterns, namely about fashion patterns, arm patterns, skirt pattern, and change the pattern according to the model.

Table 6. Hypothesis Test

\begin{tabular}{ccccccc}
\hline Data & Class & Average & $\begin{array}{c}\text { Stan-dard } \\
\text { Deviation }\end{array}$ & $t_{\text {count }}$ & $t_{\text {table }}$ & Deci-sion \\
\hline $\begin{array}{c}\text { Control class } \\
\text { Basic Pattern Learning } \\
\text { Outcomes }\end{array}$ & $\begin{array}{c}\text { Experimen } \\
\text { tal class }\end{array}$ & 72,03 & 14,16 & - & & \\
& & 10,82 & 1,67 & $\mathrm{H}_{\mathrm{a}}$ accepted \\
\hline
\end{tabular}

The results of the calculation of the average value of basic learning outcomes in conventional learning patterns are (57.03) with standard deviations (14.16). While the average value of learning outcomes given memorization learning model is (72.03) with standard deviation (10.82). From the average results, a t-test analysis was conducted between the learning outcomes in both classes. The results of the $t$ test calculation obtained the price of $t$ count (-4.761). When compared with $t$ table at df (62) that is equal to (1.67). Then the value - $t$ count $<$ t table or $(-4,761<1,67)$, which means that the alternative Hypothesis $(\mathrm{Ha})$ is accepted. Thus, the hypothesis which states that there is an influence of memorization learning model on the proven learning outcomes. Then it was concluded that learning outcomes that were given memorization learning models were higher than learning outcomes using conventional learning. The memorization learning model is a model that is directed to develop students' ability to absorb and integrate information so that they can remember information that has been received and recalled at the time it is needed.

Then the writings of Khamees, Khalid [6] and Klemm [7], explained that learning with memorization learning models can increase learning motivation in memorizing in students with low cognitive, it is important to know the teacher to emphasize the importance of understanding, but not ignoring skills memorize. While education theory includes attributes such as insight, creativity, inquiry learning, and self-expression, and leads to bias and lack of respect for the role of memory in learning. Students cannot apply what they understand if they don't remember it, and good memories expand cognitive abilities.

Furthermore Michael A. Conditt, Francesca Gandolfo, and Ferdinando A. Mussa-Ivaldi wrote Taken together, the articles remind us that individual cognition, while not only inlearning factors, is a central determining feature of learning [8]. However, we must work to further develop the present partial theory of conceptual change to fill in the missing cognitive 
core of the present shell. This memorization model is useful for balancing the functions of both the brain, the left brain and the right brain in processing the information obtained. The left brain is a brain that is logical, successive, and partial and tends to process information one by one, while the right brain thinks randomly, holistically and creatively in receiving and storing information.

Often students find it difficult to memorize because in learning students often use half of the ability of the left brain only and usually students must think sequentially and logically even though the right brain should also be used because the right brain is very helpful in the process of memorizing fast, and thinking creatively. With the balance of using the left brain and right brain together can improve the effectiveness of learning. So by using memorization learning models everything related to memorization will not be difficult and becomes a very pleasant thing. The use of the Memorization model of basic learning patterns is expected to make students more creative to improve memory power and make the material of fashion patterns a fun thing and not a boring thing anymore. If students already have an assumption that learning is a fun thing, it is hoped that this will improve student achievement and learning outcomes..

\section{Conclusion}

The results obtained from the results of data analysis and testing hypotheses can be concluded as follows: First, learning outcomes taught using conventional learning tend to be less with the average (57.03). Second, learning outcomes given memorization learning models tend to be quite average (71.48). Third, there is a significant influence between memorization learning model on the basic learning outcomes of the pattern, so it can be concluded that the learning outcomes Basic patterns given memorization learning model are better than learning outcomes that use conventional learning. Based on the results of the study and testing the hypothesis that by applying memorization learning models can improve student learning outcomes and better than student learning outcomes taught with conventional learning.

\section{References}

[1] D. Ampera, "Guru Sebagai Potensi Teknologi Informasi Dan Komunikasi Dalam Peningkatan Mutu Pembelajaran Di SMK," in Seminar Internasional, ISSN 1907-2066 Peran LPTK Dalam Pengembangan Pendidikan Vokasi di Indonesia, 2012.

[2] B. et al Joyce, Model of Teaching. Boston: Allyn and, 2009.

[3] Syahrul, "Model dan Sintak Pembelajaran Konvensional," 2013. .

[4] M. Kholik, "Metode Pembelajaran Konvensional," 2011. .

[5] D. Ampera, "Student Learning Strategi and Soft-Skill in Clothing Business Management," in IOP Comperence Series Materials Science and Engginering, 2018, vol. Volume 306.

[6] K. Sabie Khamees, "An Evaluative Study of Memorization as a Strategy for Learning English,” Int. J. English Linguist., vol. 6, no. June 29, 2016.

[7] W. R. Klemm, "What Good Is Learning If You Don’t Remember It?,” Eff. Teach., vol. 7, pp. 61-73, 2017.

[8] M. A. Conditt, F. Gandolfo, and F. A, "Neurophysiology the American Physiological Society," vol. 78, 1997. 